
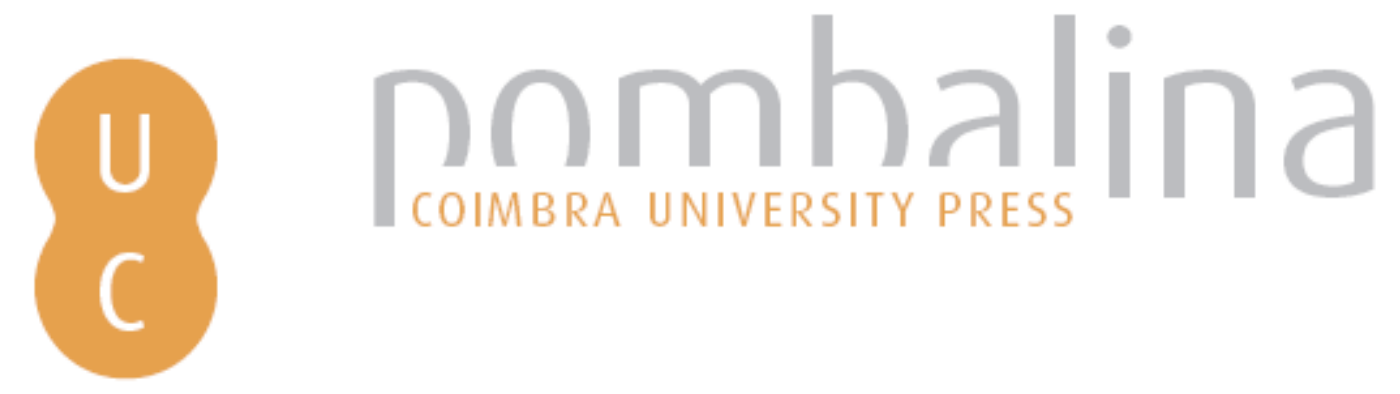

\title{
Produção de escândalo e deveres funcionais
}

Autor(es): Henriques, Paulo Videira

Publicado por: Imprensa da Universidade de Coimbra

URL

persistente: $\quad$ URI:http://hdl.handle.net/10316.2/38564

DOI: $\quad$ DOI:http://dx.doi.org/10.14195/978-989-26-0770-2_3

Accessed : $\quad$ 26-Apr-2023 10:31:21

A navegação consulta e descarregamento dos títulos inseridos nas Bibliotecas Digitais UC Digitalis, UC Pombalina e UC Impactum, pressupõem a aceitação plena e sem reservas dos Termos e Condições de Uso destas Bibliotecas Digitais, disponíveis em https://digitalis.uc.pt/pt-pt/termos.

Conforme exposto nos referidos Termos e Condições de Uso, o descarregamento de títulos de acesso restrito requer uma licença válida de autorização devendo o utilizador aceder ao(s) documento(s) a partir de um endereço de IP da instituição detentora da supramencionada licença.

Ao utilizador é apenas permitido o descarregamento para uso pessoal, pelo que o emprego do(s) título(s) descarregado(s) para outro fim, designadamente comercial, carece de autorização do respetivo autor ou editor da obra.

Na medida em que todas as obras da UC Digitalis se encontram protegidas pelo Código do Direito de Autor e Direitos Conexos e demais legislação aplicável, toda a cópia, parcial ou total, deste documento, nos casos em que é legalmente admitida, deverá conter ou fazer-se acompanhar por este aviso.

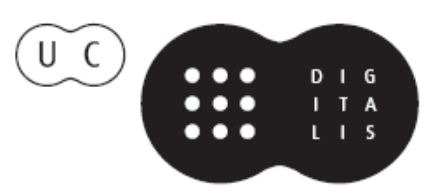



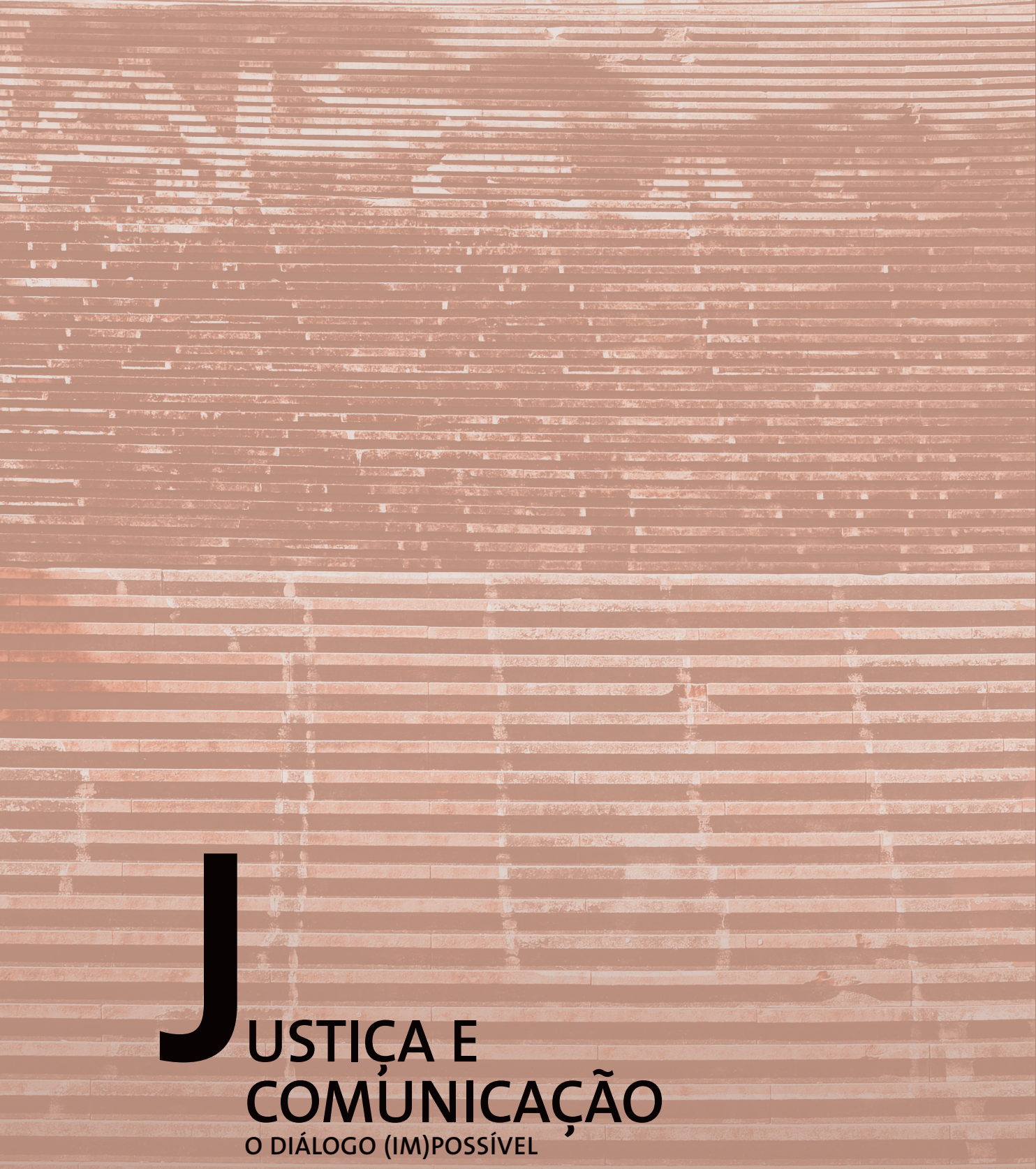

Rita Basilio Simões

Carlos Camponez

Ana Teresa Peixinho

ORGANIZAÇÃO 


\section{Paulo Videira Henriques}

(Faculdade de Direito da Universidade de Coimbra)

PRODUÇÃO DE ESCÂNDALO E DEVERES FUNCIONAIS

\section{Produção de escândalo mediático}

A produção de escândalo mediático é um agregado heterogéneo de fenómenos da comunicação de massas que podem ser assim descritos: a imputação a alguém, no espaço mediático, de factos que implicam transgressões a valores, normas ou expectativas, proporcionando a oportunidade da respetiva apreciação pelos públicos e potenciando uma reação geral de desaprovação do apontado transgressor ${ }^{43}$.

Desse agregado consideram-se apenas, no presente texto, aqueles escândalos mediáticos que exibem, como nota comum, a circunstância de estarem relacionados com investigações policiais ou com processos e decisões judiciais; trata-se, por conseguinte, de situações do mundo da vida que constituem assunto forense e que são abordadas na comunicação mediática no formato de escândalo. Repare-se que o perímetro que assim se desenha não coincide integralmente com as linhas de fronteira do escândalo político: por um lado, há escândalos políticos sem ligação a assuntos forenses e, por outro lado, também há escândalos cujo enredo não contempla personagens da política ${ }^{44}$. Cumpre notar, igualmente, que a produção de escândalo mediático explora os territórios do processo

\footnotetext{
43 Cfr., por todos, THOMPSON (2002, pp. 40-50).

${ }^{44} \mathrm{O}$ escândalo político representa um importante segmento da produção de escândalo mediático e concita, ainda que sob designações muito diversas, crescente atenção científica; por exemplo: GARMENT (1991); JIMÉNEZ SÁNCHEZ (1994); CASTELlS (1999: 391-401); PAIXÃO (2010).
} 
penal, nomeadamente com os chamados julgamentos mediáticos ${ }^{45}$, mas também se aventura com sucesso noutros domínios do campo da justiça ${ }^{46}$.

A proliferação de séries de escândalos mediáticos permite verificar, além do mais, que a empresa de comunicação é capaz de recolher qualquer evento da realidade judiciária, o qual passa a constituir matéria-prima de conteúdos mediáticos e, como tal, é submetido ao tratamento que melhor adeque tais conteúdos à fase evolutiva em que se encontrar o pertinente escândalo ${ }^{47}$; por outras palavras: a empresa de comunicação produz e divulga os conteúdos informativos de temas judiciários em formatos de entretenimento. Ora, como é sabido, é justamente por dar prioridade à estimulação de sensações e emoções que o formato de entretenimento permite disputar a atenção de uma massa imensa de destinatários que não se fixam em programas de "informação séria" - muitos desses destinatários nem cultivam o género de competências ou interesses intelectuais a que é suposto dirigir-se a "informação séria”, destilada em conteúdos objetivos mas emocionalmente neutros ${ }^{48}$. Por conseguinte, será certamente

45 Na lição de SURETTE (2010), a expressão julgamento mediático refere situações que podem ser descritas como segue: a propósito de um julgamento ou outro evento judicial, os media recorrem ao sistema de justiça como uma fonte de drama, entretenimento e receita; os julgamentos selecionados são transformados ou socialmente construídos (construção social do conhecimento) como produtos ou mercadorias de infotainment para comercialização em massa; sempre que possível a cobertura é em direto, as imagens têm preferência sobre o texto e o conteúdo é caracterizado por conjeturas dirigidas primacialmente aos sentidos (sensacionalismo); sobre as consequências da rendição ao sensacionalismo, no contexto da justiça criminal dos E.U.A., cfr. igualmente FOX \& VAN SICKEL (2001).

46 Por exemplo: processos de regulação da responsabilidade parental propiciaram, entre nós, a produção de duas séries de escândalos mediáticos, com os títulos "Caso Esmeralda" e "Caso Alexandra".

47 Não está fixada uma estrutura rígida que a sequência de atos e cenas do escândalo deva necessariamente observar. Contudo, refletindo uns instantes sobre a prática provável de uma organização empresarial de comunicação social, cuja atividade inclua a produção reiterada do bem imaterial a que chamamos escândalo mediático, parece razoável supor que tal empresa não desprezará, até por necessidade de sistematização das rotinas produtivas, indicações das técnicas de cativação da atenção do público, algumas já praticadas no teatro grego, designadamente a apresentação de uma sequência de mensagens numa gradação crescente ou decrescente dos efeitos emotivos. A este respeito, e não obstante algumas divergências académicas sobre os critérios de divisão das várias fases do escândalo, os autores tendem a convergir na ideia de que a produção de escândalo observa a estrutura narrativa do drama: para um panorama geral da literatura, cfr., por todos, PAIXÃO (2010:45-48), com indicações bibliográficas.

48 Os autores que investigam a história do jornalismo verificam que já no século XIX a imprensa contemplava em simultâneo peças de informação e de entretenimento: SCHUDSON (1978), WIENER (1988), ESSER (1999). Vendo a forma, por exemplo, como a 


\section{de alguma utilidade para a organização de comunicação mediática, en-}

quanto empresa comercial, a aposta na produção de escândalo, como produto de convergência entre informação e entretenimento (o chamado infotainment ${ }^{49}$ ).

imprensa da época fez a cobertura dos crimes de Jack o Estripador (CURTIS, 2001, em especial os capítulos $3 .^{\circ}$ e $4 .^{\circ}$ ) parece haver alguma semelhança entre o new journalism e a imprensa sensacionalista contemporânea. Mas pode inclusivamente questionar-se o acerto da contraposição, no contexto de peças jornalísticas, entre notícias (news) e entretenimento (entertainment) ou, inclusivamente, entre jornalismo de atualidade política e jornalismo popular (CARPINI \& WILLIAMS, 2001).

${ }^{49}$ Embora o Oxford Dictionary of English apresente uma descrição neutra de infotainment - «difusão de conteúdo destinado simultaneamente a informar e a entreter» -, a verdade é que este termo ganhou um significado pejorativo, passando a exprimir o desagrado com as duas faces de uma mesma moeda: numa face, o recuo do tempo dedicado, em televisão, ao tratamento noticioso, por jornalistas profissionais, de assuntos de interesse público; na outra face, a proliferação de conteúdos destinados a satisfazer a curiosidade dos públicos acerca das trivialidades dos famosos ou a servir doses diárias de escândalos políticos, empresariais e judiciários. O crescimento do infotainment parece ter múltiplas associações a fatores heterogéneos, sem que se possa estabelecer, com segurança, um quadro de relações causais. Parte da explicação poderá assentar na predominância global da televisão privada, gerida com objetivos comerciais. Mas ao mesmo tempo terá ocorrido uma evolução, com algum significado, na própria visão teórica da comunicação: transitou-se de uma conceção qualitativa (descrição, relato, testemunho e perspetiva - exteriorizados através de uma linguagem comum a emissor e recetor -, através dos quais se procede à análise, à classificação e à formulação de opiniões e juízos sobre a realidade; se reportada à realidade presente, denomina-se informação de atualidade e traduz-se na produção de um bem imaterial, as notícias; ao jornalista cumpre, precisamente, procurar, organizar e dar forma às notícias) para uma conceção quantitativa (fazer passar, através de um canal, o máximo de informação com o mínimo de distorção e com a máxima economia de tempo e de energia; a mensagem deve revestir a forma e o conteúdo que, por um lado, tornem mais instantânea e discreta a intervenção do medium e, por outro lado, diminuam o esforço e os meios necessários à fixação das atenções pelo maior número possível de recetores). Por outro lado, as sucessivas transformações tecnológicas ocorridas viabilizam a satisfação de uma necessidade - estar presente no setor da comunicação mediática - a um número maior de grupos económicos, necessidade que a própria centralidade do campo da comunicação tem feito proliferar. Daí decorre a multiplicação de canais televisivos e, consequentemente, aumenta a competição por públicos e por receitas publicitárias. Entretanto, em contraste, as oportunidades de economias de escala ou de reaproveitamento de conteúdos suscitam estratégias de concentração e de parceria; nesta tendência, a ligação de canais televisivos a atividades de produção de entretenimento (cinema, música, teatro, séries televisivas, parques de diversões, internet) merece particular atenção por diversas razões: seja pela sua frequência, seja pela consequente reserva de espaço televisivo para ocupar com as celebridades do mundo do espetáculo, seja ainda pela popularidade dos produtos que exploram a apetência geral pela obtenção do estatuto de famoso, sujeitando os concorrentes a uma demonstração mediática de habilidades cada vez mais insólitas. Estes e outros fatores conjugam-se para a diminuição do espaço reservado às notícias e para a diluição das fronteiras teóricas entre informação, documentário e entretenimento. No contexto sumariamente descrito, a produção de escândalo mediático sobre matérias judiciárias reforça, precisamente, o jornalismo de entretenimento (FRANKLIN, 1997), (THUSSU, 2007). 
Todavia, quando passamos para o campo da justiça, o fenómeno ganha de imediato outros matizes: a produção de escândalo mediático aprofunda dificuldades bem conhecidas e é fonte de acrescidos embaraços ${ }^{50}$.

Quando o escândalo mediático explora temas da realidade judiciária, a respetiva produção tende a envolver, nas suas diversas fases, a presença e a participação, ainda que involuntária, de profissionais da justiça. Ou seja: pessoas que exercem uma atividade profissional nas diversas fases dos processos judiciários (juízes, procuradores, advogados, funcionários de justiça, polícias, peritos, consultores técnicos) são compelidas - seja, ou não, do seu agrado - a comprometer-se em papéis que a produção mediática lhes vai destinando à medida que o escândalo evolui.

O comprometimento pode ocorrer, desde logo, no período de antestreia do escândalo: frequentemente, as indiscrições e os comentários sobre a transgressão animam, durante algum tempo, os fluxos comunicativos nos círculos restritos dos profissionais da justiça, sem alcançar, contudo, a dimensão técnica de um escândalo, por (ainda) não ter irrompido na praça pública $^{51}$. Ademais, como algumas vozes têm advertido, também se não afigura inverosímil que, por vezes, a mediatização da alegada transgressão assente na informação propalada, sob anonimato, pelos próprios profissionais

50 Alguns estudos identificam o risco de concorrência entre duas versões de justiça, a legítima e a do infotainment: cfr. MACHADO \& SANTOS (2008) e (2009), com indicações bibliográficas. Na perspetiva dos críticos mais pessimistas, para além da supremacia desregulada da lógica da empresa mercantil, pior do que a emergência do "quarto poder", a produção do escândalo mediático geraria um risco de subversão dos poderes legítimos: a um sistema de justiça orientado para o respeito dos direitos humanos e do primado da lei, o campo da comunicação mediática viria contrapor, como alternativa de organização social, a sua versão infotainment de justiça, serventuária das inclinações efémeras das massas. Avançando por esta linha de raciocínio, quiçá incorrendo naquele mesmo excesso de dramatismo que justamente se pretende exorcizar, dir-se-ia que a radicação da versão infotainment de justiça materializaria o risco daquela forma de degenerescência da demo-

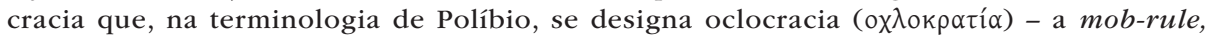
na tradução inglesa de PATON (1922: 274-275), mas ver também BOBBIO (1982: 66-67) -, correspondente ao jugo imposto pelas multidões que fazem valer a licenciosidade e a arbitrariedade, em desrespeito da Constituição e da lei, por a opinião maioritária passar a constituir, em qualquer situação, o decisivo critério de validade.

51 As informações sobre uma transgressão podem ser partilhadas, em comunicação interpessoal, entre os membros de uma rede de conhecimento sem que se possa falar, ainda, em escândalo mediático: o momento em que nasce o escândalo "é o momento em que se torna público um ato ou uma série de atos até então mantidos em segredo ou ocultos (...)» (BOBBIO, 2000: 105). 
da justiça ${ }^{52}$. Depois, como é sabido, uma vez lançado o escândalo, muitos profissionais sentem-se compelidos a esclarecer e discutir o assunto em territórios retóricos que não são os da justiça ${ }^{53}$; desta feita podemos assistir, em cada novo episódio de escândalo mediático, a desempenhos peculiares de alguns profissionais da justiça: convive-se bem com a discussão fora dos autos; não se desprezam os ataques pessoais ou os efeitos de vitimização; ensaiam-se frases sensacionalistas com impacto mediático; promovem-se eventos com o fito exclusivo de obter cobertura mediática ${ }^{54}$.

Podemos admitir, portanto, que a participação dos profissionais de justiça nos episódios dos escândalos mediáticos pode contribuir, ainda que involuntariamente, para o reforço de perceções negativas sobre a administração da justiça; e um desses incidentes pode até produzir efeitos negativos mais duradouros do que os danos eventualmente resultantes do exercício, pelos jornalistas, do "direito à crítica judiciária" 55 . Conviria então, até por isso, que no campo da justiça se enfrentasse, com eficácia, o fenómeno da produção de escândalos mediáticos sobre temas judiciários, porventura atribuindo prioridade às tarefas de definição e articulação de estratégias profissionais de comunicação, nomeadamente ponderando soluções que já mostraram virtualidades noutras ordens jurídicas ${ }^{56}$. Em todo o caso, a nota que neste nosso encontro pretendo salientar consiste, recorde-se, no reconhecimento de uma tendência empírica: quando o escândalo mediático explora temas da realidade judiciária, a respetiva

52 CONDE FERNANDES (2008: 336) afirma-o de modo incisivo: "Na regra prevalecente da ocultação da identidade, presume-se, pelo teor das próprias notícias, que [as fontes] serão advogados, funcionários judiciais, polícias, mas também magistrados, ou intervenientes processuais ocasionais, como arguidos, testemunhas e ofendidos, pois que serão os únicos em quem os jornalistas podem acreditar - com alguma fé - disporem de informação com valor noticioso e - com muita fé - quererem-na confiar com verdade e isenção, a coberto do anonimato".

53 Cfr. uma descrição exemplificativa em BARREIROS (2005: 166).

54 De facto, todo um cortejo de papéis dramáticos que indicia estar a acontecer no campo da justiça, em Portugal, um processo de progressiva e crescente mediatização, com a ocorrência de fenómenos de acomodação ou mesmo de adoção da lógica dos media, com as funções e características apontadas por JHARVARD (2008) e SCHULZ (2004), mas cuja explicitação exorbita do âmbito do presente texto.

55 Sobre o direito à crítica judiciária e a publicidade mediada, cfr. FILIPE MATOS (2011: 31-34).

56 Cfr., por exemplo, RUI DO CARMO (2005: 158-161) e CONDE FERNANDES (2008: 339). 
produção tende a implicar a comparência, voluntária ou involuntária, dos profissionais de justiça, no campo da comunicação social.

\section{Deveres funcionais - o dever de reserva}

Nas sociedades democráticas contemporâneas, o direito à liberdade de expressão é um direito fundamental de que goza toda a pessoa 57 . O facto de ser fundamental não significa, contudo, que o direito à liberdade de expressão seja imune a limites e restrições; não há direitos fundamentais ilimitados. Acresce que o âmbito concreto do direito à liberdade de expressão não é uniforme ou idêntico para todas as pessoas: a sua conformação efetiva varia em virtude de fatores diversos, incluindo o tipo de estrutura comunicativa em causa e a posição em que nela se encontra o titular do direito ${ }^{58}$.

Servem estas considerações, consabidas, apenas para recordar que os catálogos legais e deontológicos dos profissionais de justiça impõem restrições à respetiva liberdade de expressão, mormente estabelecendo deveres de sigilo e deveres de reserva na comunicação extraprocessual.

Fixando-nos no dever de reserva, a consulta aos estatutos profissionais permite surpreender as formulações que seguidamente se transcrevem:

"Os funcionários em serviço na PJ não podem fazer revelações públicas relativas a processos ou sobre matérias de índole reservada, salvo o que se encontra previsto nesta lei sobre informação pública e ações de natureza preventiva junto da população e ainda o disposto nas leis de processo penal ${ }^{59}$."

"São ainda deveres dos funcionários de justiça não fazer declarações ou comentários sobre processos, sem prejuízo da prestação de informações que constituam atos de serviço ${ }^{60}$."

57 Cfr., por todos, CANOTILHO \& MOREIRA (2007), JÓNATAS MACHADO (2002).

58 Neste sentido, por todos, JÓNATAS MACHADO (2002:391-392).

59 Texto do.$^{\circ}$, do artigo $13 .^{\circ}$, da Lei Orgânica da Polícia Judiciária (Lei n. ${ }^{\circ}$ 37/2008, de 6 de agosto, na redação em vigor).

60 Texto da alínea $a$ ), do artigo $66 .^{\circ}$, do Estatuto dos Funcionários de Justiça (Decreto-Lei n. ${ }^{\circ} 343 / 99$, de 26 de agosto, na redação em vigor). 
"O advogado é indispensável à administração da justiça e, como tal, deve ter um comportamento público e profissional adequado à dignidade e responsabilidades da função que exerce (...).

O advogado está obrigado a defender os direitos liberdades e garantias, a pugnar pela boa aplicação das leis, pela rápida administração da justiça e pelo aperfeiçoamento da cultura e instituições jurídicas ${ }^{61 . "}$

"Os magistrados do Ministério Público não podem fazer declarações ou comentários sobre processos, salvo, quando superiormente autorizados, para defesa da honra ou para realização de outro interesse legítimo.

Não são abrangidas pelo dever de reserva as informações que, em matéria não coberta pelo segredo de justiça ou pelo sigilo profissional, visem a realização de direitos ou interesses legítimos, nomeadamente o do acesso à informação ${ }^{62}$."

"Os magistrados judiciais não podem fazer declarações ou comentários sobre processos, salvo, quando autorizados pelo Conselbo Superior de Magistratura, para defesa da honra ou para a realização de outro interesse legítimo.

Não são abrangidos pelo dever de reserva as informações que, em matéria não coberta pelo segredo de justiça ou pelo sigilo profissional, visem a realização de direitos ou interesses legítimos, nomeadamente o do acesso à informação ${ }^{63}$."

Como se vê do exposto, as restrições às liberdades de expressão e de comunicação não são aplicáveis somente aos magistrados: aplicam-se a todas as profissões forenses. Por isso, a meu ver, a respetiva justificação deve ser procurada, desde logo, no plano global da administração da justiça e não apenas no perímetro, mais especializado, das missões das magistraturas. Na verdade, a administração da justiça é uma obra coletiva: cada profissão

61 Texto do n. ${ }^{\circ} 1$ do artigo $83 .{ }^{\circ}$ e do n. ${ }^{\circ} 1$ do artigo $85 .^{\circ}$, ambos do Estatuto da Ordem dos Advogados (Lei n. ${ }^{\circ}$ 15/2005, de 26 de janeiro).

62 Texto do artigo $84 .^{\circ}$ do Estatuto do Ministério Público (Lei n. ${ }^{\circ}$ 47/86, de 15 de outubro, republicada pela Lei n. ${ }^{\circ} 60 / 98$, de 27 de agosto, na redação em vigor).

63 Texto do artigo $12 .{ }^{\circ}$ do Estatuto dos Magistrados Judiciais (Lei n. ${ }^{\circ}$ 25/85, de 30 de julho, na redação em vigor). 
do campo da justiça concorre, na sua missão específica, para o sucesso e para o fracasso da administração da justiça. São os desempenhos coletivos alcançados através da concertação das ações de profissionais dos diversos ofícios que permitem conquistar, de facto, a autonomia e independência do campo da justiça. E ao referir estas características do campo da justiça - autonomia e independência - aquilo que se pretende significar corresponde essencialmente às seguintes capacidades do sistema de justiça: por um lado, o sistema deve ser capaz de decidir a favor de um cidadão ou de uma organização, exclusivamente em função da lei e das provas legítimas produzidas no processo, apesar de a respetiva condenação ser pedida por algum poderoso ou pela opinião pública; por outro lado, inversamente, o sistema também deve ser capaz de decidir contra um cidadão ou uma organização, exclusivamente em função da lei e das provas legítimas produzidas no processo, apesar de a respetiva absolvição ser pedida por algum poderoso ou pela opinião pública; em terceiro lugar, o sistema deve ser capaz de exercer com regularidade as capacidades anteriormente descritas; last, not the least, o sistema deve ser capaz de mostrar continuamente à comunidade que está a exercer com regularidade aquelas capacidades.

Consequentemente, os objetivos ou finalidades de atuação dos diversos profissionais de justiça devem contemplar não só o funcionamento regular das instâncias jurídicas mas também a produção, nos cidadãos, de confiança na ação da administração da Justiça. Ora, a meu ver, é precisamente com a satisfação destes objetivos que se deve relacionar a disciplina legal, enunciada nas normas que se transcreveram, acerca das declarações e comentários dos profissionais de justiça. De facto, quando expõe na comunicação social os detalhes do processo que tem em mãos ou quando aceita participar na apreciação mediática das incidências da controvérsia, qualquer profissional de justiça se arrisca a semear, com tais comportamentos, a suspeita de que o sistema de justiça não é capaz de enfrentar o assunto (daí a fuga para a praça pública). Quando dá a conhecer uma perspetiva individual ou manifesta escolhas e inclinações pessoais sobre o assunto, abstraindo do rito processual e das contingências da prova, o profissional de justiça pode estar a oferecer argumentos a quem pretenda fomentar dúvidas sobre os métodos de trabalho em uso na 
justiça - materializadas em hipóteses de conspiração, de obstinação na investigação de certos grupos, de juízos predeterminados, etc. Depois, como a apreciação mediática não tem de obedecer aos parâmetros por que se orienta a justiça (pois, como é evidente, a opinião de cada cidadão e as paixões das massas nunca são formadas com base exclusivamente na lei e nas provas legítimas produzidas nos autos), o resultado final também pode gerar desconfiança: os públicos tomam imediatamente partido e dividem-se nos prognósticos, pelo que a ação da justiça contrariará sempre as expectativas de muitos. Estamos, pois, em condições de identificar alguns riscos para o campo da justiça que são gerados ou reforçados por declarações, opiniões e comentários dos profissionais de justiça - daí que se justifique regular tais comportamentos através de deveres funcionais. Não se pense, porém, que a alusão a estes riscos tem o propósito de verberar toda e qualquer expressão comunicativa da parte dos profissionais de justiça. Tanto mais que, em rigor, perante o atual contexto de mediatização da justiça, mesmo seguindo um fio de raciocínio que não respeitasse o valor constitucional da liberdade de expressão, sempre cumpriria identificar um outro risco, a saber: o risco de o silêncio dos profissionais de justiça ser negativamente valorado pela comunidade e constituir, por isso mesmo, um motivo de desconfiança na administração da justiça. Não se trata, repetimo-lo, de neste momento assumir qualquer posição normativa. Por agora, apenas se está a descrever algumas das linhas de força em confronto, para melhor enfatizar o seguinte: o exercício das liberdades de expressão e comunicação dos profissionais de justiça está em permanente tensão com as limitações resultantes do dever de reserva. Naturalmente, a popularidade dos escândalos mediáticos sobre temas judiciários vem aumentar, pelo menos quantitativamente, as manifestações daquela tensão e, ao mesmo tempo, reforça a respetiva visibilidade social, circunstância que também não facilita a superação cordata dos incidentes.

Façamos então uma síntese do caminho até aqui percorrido. Começámos por explicar que o escândalo mediático implica a comparência dos profissionais da justiça no campo da comunicação social e sublinhámos, em seguida, que tal comparência ocorre no exercício das suas liberdades de expressão e comunicação. Relembrámos, depois, que as condutas 
expressivas podem ter, todavia, consequências menos felizes para a confiança na administração da justiça - e é precisamente nesta vertente, de apreciação do impacto da conduta expressiva, que são aplicáveis os deveres funcionais, mormente o dever de reserva. Aqui chegados, para resumir o entendimento exposto, podemos talvez formular, em termos genéricos, a seguinte proposição: relativamente a matérias judiciárias há declarações, opiniões e comentários que são juridicamente tolerados quando feitos por jornalistas, por políticos ou pelo cidadão anónimo mas que já merecem censura jurídica - por violação dos deveres funcionais de reserva - quando são emitidos por magistrados, por advogados ou por outros profissionais de justiça.

\section{O dever de reserva dos magistrados judiciais}

As observações expendidas nos pontos anteriores têm em vista todos os profissionais de justiça. Não se ignora, contudo, que o debate é mais intenso quando se trata do comportamento de um juiz ${ }^{64}$. A meu ver, a conciliação entre a liberdade de expressão e o dever de reserva dos juízes pode mesmo integrar o grupo dos desafios de maior melindre que atualmente se colocam aos juristas no estudo das relações entre a justiça e a comunicação ${ }^{65}$. Nesta matéria as hesitações são intensas, como ficou

64 Como ilustra, nomeadamente, a Ata n. ${ }^{\circ}$ 9/2008 (11.3.2008) do Conselho Superior de Magistratura, na qual se relata o debate e a votação de uma deliberação genérica sobre o entendimento do dever de reserva, tomada pelo Plenário do Conselho Superior de Magistratura, em sessão extraordinária que teve lugar naquela data.

65 Uma das maiores ameaças à confiança na administração da justiça é a progressiva popularidade da perceção segundo a qual os magistrados são, primeiro, políticos, só depois, decisores imparciais. O problema reveste ainda maior acuidade naquelas ordens jurídicas, como sucede em muitos Estados norte-americanos, que recrutam os magistrados através de eleições periódicas, por voto popular, precedidas de campanhas eleitorais muito disputadas e financiadas por particulares. De facto, a experiência ensina que as incidências típicas de qualquer campanha eleitoral suscitam condutas expressivas pouco compatíveis com as implicações da imparcialidade e da independência - e como conciliar, no calor de campanhas personalizadas, a necessidade de diferenciação do candidato com a promessa de que será dada preferência, no exercício de funções, ao direito constituído em detrimento de opiniões e convicções pessoais? Sobre a situação nos E.U.A. após a decisão do Supremo Tribunal no caso White, cfr., por exemplo, GEYH (2006) e WEICHER \& GOLDSCHMIDT (2007). 
patente, aliás, em recente decisão do Tribunal Europeu dos Direitos do Homem $^{66}$, pelo que, por agora, as divisões são praticamente inevitáveis ${ }^{67}$.

No estudo dos problemas talvez seja útil recordar, para evitar erros de análise, que o dever de reserva dos magistrados é uma figura antiga $^{68}$, cuja consagração ocorreu muito antes de a proteção jurídica das liberdades comunicativas ter obtido a atual extensão. A tonalidade mais antiga do dever de reserva é, pois, a menos iluminada pela liberdade de expressão. Sustenta-se, tradicionalmente, que o estatuto da magistratura deve desincentivar a exposição mundana do juiz, desde o recrutamento até ao fim da carreira. A pessoa que deseja servir na magistratura deve assumir o compromisso de respeito escrupuloso da obrigação de reserva e de silêncio mediático absoluto ${ }^{69}$. A significar, desde logo, que em caso algum deve um magistrado comentar, fora dos autos, os processos: «tem-se entendido que antes da decisão o Juiz nada tem a dizer porque ainda não está decidido; que durante o processo de decisão não há nada a dizer porque se está em plena elaboração desta e que após a decisão nada há a dizer porque tudo está dito. ${ }^{70}$ " Mas a implicar igualmente, como regra geral, que o juiz também não deve aparecer nos media para comentar outros assuntos, salvo autorização superior, em situações excecionais e para realização de algum interesse legítimo ${ }^{71}$.

66 Caso Kudeshkina v. Russia: Acórdão do TEDH de 26 de fevereiro de 2009, da Primeira Secção; a decisão que considera ter existido violação do artigo $10 .^{\circ}$ da CEDH foi tomada por 4 votos a favor e 3 votos contra, com duas declarações de voto.

67 Ainda assim, afigura-se que seria excessivo demarcar, no trabalho teórico, modelos separados e antagónicos, como se fossem as duas margens de um rio; a meu ver, o estado da questão é comparável à imagem das águas do próprio rio que vão assumindo, entre a luz e a sombra, tonalidades diferentes. É com esta ideia que se alude a várias tonalidades na exposição subsequente.

68 Cfr., por exemplo, ORLANDO AFONSO (2005: 147-151).

69 Neste sentido, por exemplo, GARAPON (1998: 263-264).

70 ORLANDO AFONSO (2004: 152).

71 O Reino Unido propicia uma boa ilustração da conceção tradicional, com as chamadas Kilmuir Rules, cuja origem se conta em breves palavras: em 1955, o Diretor-geral da BBC teria sugerido ao então Lord Chancellor, Lord Kilmuir, que os magistrados de categoria mais elevada participassem em programas de rádio onde seriam recordados os grandes juízes do passado; a resposta do Lord Chancellor foi negativa e o seu texto passou a integrar, até 1987, o regime jurídico do relacionamento dos magistrados com a comunicação mediática. Na parte mais relevante, a referida missiva estabelecia o seguinte (apud THOMAS, 1997: 93-94): 
Portanto, uma conceção que apresenta os seguintes matizes: num vasto perímetro da ação comunicativa, o juiz tem, em lugar da liberdade, uma obrigação de silêncio, cujo cumprimento pode ser, todavia, dispensado; as declarações e comentários do magistrado fora dos autos carecem de autorização prévia, sobretudo se têm lugar no campo da comunicação mediática ${ }^{72}$; a exposição mediática voluntária de um juiz sem prévia autorização pode implicar responsabilidade disciplinar.

Decerto não surpreende, atravessando nós uma época de exaltação das liberdades de expressão, que o dever de reserva esteja a ganhar outras tonalidades, menos cinzentas. O assunto começou a receber visibilidade internacional a partir dos anos 80 do século passado ${ }^{73}$. Como marco decisivo deste movimento pode apontar-se a aprovação, pela Assembleia Geral das Nações Unidas, dos Princípios Básicos Relativos à Independência da Magistratura ${ }^{74}$; o ponto 8 da parte dispositiva desse

"Todos concordamos, penso eu, que há efetivo benefício para o público quando numa emissão radiofónica são abordados, pelas mais altas autoridades, assuntos sérios e importantes. É provável, por exemplo, que se obtenha uma melhor avaliação das qualidades de algum eminente magistrado do passado através de um membro atual da magistratura do que através de qualquer outra pessoa.

Mas a consideração decisiva, na opinião da minha pessoa e dos meus colegas, é a importância de manter a magistratura isolada das polémicas do dia. Enquanto um juiz mantém o silêncio, a sua reputação de sabedoria e imparcialidade permanece inatacável; mas cada declaração que ele faz em público, exceto no curso do desempenho real das suas funções, tem necessariamente de o colocar sob o foco da crítica. Além disso, seria inadequado para a magistratura ser associada com qualquer série de palestras ou algo que possa ser razoavelmente interpretado como entretenimento; e em nenhuma circunstância, é claro, deve o juiz receber comissão relativa a uma transmissão radiofónica.

Eu e os meus colegas estamos, portanto, de acordo que, como regra geral, é indesejável para os membros da magistratura participar em emissões radiofónicas ou aparecer na televisão. Reconhecemos, no entanto, que pode haver ocasiões, por exemplo iniciativas de caridade, em que a participação de um juiz numa emissão radiofónica não suscitará oposição. Consideramos que se os juizes forem abordados pelas autoridades da emissora com um pedido para participar numa transmissão, em alguma ocasião especial, o juiz interessado deve consultar o Lord Chancellor que estará sempre pronto para manifestar o seu parecer sobre o concreto pedido."

72 Note-se, a este propósito, que o dever de reserva raramente foi invocado para objetar à participação dos magistrados em palestras, ações de formação, cursos universitários e em muitos eventos públicos ou que decorrem publicamente mas que não são produzidos no campo da comunicação mediática.

$73 \mathrm{Um}$ período muito rico em estudos, debates e instrumentos internacionais sobre as várias vertentes da independência judicial, como ilustra a obra coletiva editada por SHETREET \& DESCHENES (eds), (1985).

${ }^{74} \mathrm{O}$ texto foi adotado pelo Sétimo Congresso das Nações Unidas para a Prevenção do Crime e o Tratamento dos Delinquentes, realizado em Milão de 26 de agosto a 6 de 
instrumento estabelece ${ }^{75}$ : «Em conformidade com a Declaração Universal dos Direitos do Homem, os magistrados gozam, como os outros cidadãos, das liberdades de expressão, de crença, de associação e de reunião; contudo no exercício destes direitos, eles devem comportar-se sempre de forma a preservar a dignidade do seu cargo e a imparcialidade e a independência da magistratura».

$\mathrm{Na}$ sua aparência conservadora, pois que se limita a invocar uma liberdade expressamente reconhecida na Declaração Universal dos Direitos do Homem, a formulação supra transcrita contém todo um programa de alteração dos critérios do dever de reserva do juiz.

A alteração de maior alcance prende-se, evidentemente, com a liberdade de expressão: a capacidade de gozo dos magistrados passa a incluir o mesmo direito à liberdade de expressão que é reconhecido aos outros cidadãos; as faculdades de participação cívica, de expressão e de comunicação dos magistrados deixam de ser meramente acidentais e residuais - deixam de ser uma oportunidade incerta que eventualmente se abre depois de satisfeitas as exigências estatutárias. As duas implicações mais imediatas desta alteração decorrem de prerrogativas basilares da liberdade de expressão; em primeiro lugar, tanto a atitude de silêncio mediático como a de exposição mediática correspondem a opções individuais, no exercício daquela liberdade, pelo que já não podem ser valoradas como cumprimento ou violação de uma obrigação de silêncio; em segundo lugar, é ilícito qualquer constrangimento imposto por outrem, mesmo sob a forma de sujeição a autorização prévia, para o juiz dizer ou escrever o que

setembro 1985, e aprovado pelas resoluções da Assembleia Geral n. ${ }^{\circ}$ 40/32 de 29 de novembro de 1985 e n. ${ }^{\circ} 40 / 146$ de 13 de dezembro de 1985. Por sua vez, o texto dos Procedimentos para a Efetiva Implementação dos Princípios Básicos (resolução 1989/60, aprovada na 15. a reunião plenária, em 24 de maio de 1989, do Conselho Económico e Social) estabelece, entre o mais, o seguinte (Procedimento 4): "Os Estados devem assegurar que os Princípios Básicos são amplamente divulgados, pelo menos na língua principal, na lingua oficial ou nas línguas oficiais do país respetivo. Os juízes, os advogados, os membros do Governo, os deputados e o público em geral devem ser informados, da forma mais adequada, sobre o conteúdo e a importância dos Princípios Básicos para que possam promover a sua aplicação no âmbito do sistema de justiça. Os Estados devem disponibilizar o texto dos Princípios Básicos, especialmente a todos os membros da magistratura."

75 Formulação praticamente semelhante veio a ser acolhida no ponto 8 da versão final, de 1989, da Draft Universal Declaration on the Independence of Justice ("Singhvi Declaration"). 
entender. Por outro lado, a apreciação jurídica (deontológica) muda o seu campo de incidência. Relativamente à prática da conduta expressiva, o juiz passa a decidir, por si, como os outros cidadãos, se emite a declaração ou o comentário, como, quando e onde comunica, e qual o respetivo propósito; nesta fase, as questões tendem a sair do plano jurídico ou deontológico, ficando somente no plano da ética. É somente ao exame das consequências da declaração ou do comentário que a apreciação jurídica (deontológica) pode ser dirigida: se a conduta expressiva for adequada a beliscar a dignidade do cargo ou a independência da magistratura pode haver violação do dever de reserva ${ }^{76}$. Outra área que sofre modificação tem que ver com as perceções de imparcialidade: mesmo que sejam proferidas num tom informal, as declarações emitidas na comunicação mediática constituem uma ocorrência que fica em arquivo nos media ou na Internet; consequentemente, tudo aquilo que um juiz afirma numa aparição mediática pode mais tarde ser usado para debater - quer no campo da justiça, quer no da comunicação mediática - a suspeição desse juiz, no dia em que lhe for distribuído um processo cujo objeto verse a temática em causa naquela ocorrência.

76 Cfr. LAMBERT (2004: 15); VERDUSSEN (2004: 22); CANIVET \& JOLY-HURARD (2004: 88-89). 


\section{B I B L I O G R A F I A}

AFONSO, O. (2005). "Dever de reserva - O seu papel na jurisdição". In: AA VV, Balanço da reforma da acção executiva. Segredo de justiça e dever de reserva (Conselho Superior da Magistratura, II Encontro Anual - 2004). Coimbra: Coimbra Editora, pp. 147-154.

ALBINO, C. (2003). «Sim, a Ordem dos Jornalistas». In: Diário de Notícias, 2 de novembro.

AMSELEK, P. (1964). Méthode phénoménologique et théorie du droit. Paris: L.G.D. J.

ANTUNES, F. (1994). "Alta Autoridade está queimada». In: Jornal de Notícias, 14 de março.

AZNAR, H. (2005). Comunicação Responsável - A auto-regulação dos media. Porto: Porto Editora.

BARREIROS, J. A. (2005). "O dever de reserva nas profissões jurídicas». In: AA VV, Balanço da reforma da acção executiva. Segredo de justiça e dever de reserva (Conselho Superior da Magistratura, II Encontro Anual - 2004). Coimbra: Coimbra Editora, pp. 163-170.

BARTHES, R. (1984). O rumor da língua. Lisboa: Ed. 70, (trad. portuguesa).

BECKETT, K. e WESTERN, B. (2001). "Governing social marginality: welfare, incarceration and the transformation of state policy". In: Punishment and Society, 1, pp. 43-59.

BENHABIB, S. (2009). "Rumo a um modelo deliberativo de legitimidade democrática». In: MARQUeS, A. (ed.), A Deliberação Pública e suas Dimensões Sociais, Políticas e Comunicativas. Belo Horizonte: Autêntica Editora.

BERGEL, J-L. (1997). "Du concept de déontologie à sa consécration juridique». In: BERGEL, J-L, (org.), Droit et Déontologies Professionnelles. Aix-en-Provence: Librairie de l'Université.

BHATIA, V. K. (1993). Analysing Genre: Language Use in the Professional Setting. London: Longman.

BHATIA, V. K. (1994). Cognitive structuring in legislative provisions. In: GIBBONS, J. (ed.). Language and the Law. London: Longman.

BHATIA, V. K. (2010). Legal writing: specificity. Specification in legislative writing: accessibility, transparency, power and control. In: Coulthard, M. e Johnson, A. (eds.) 2010. The Routledge Handbook of Forensic Linguistics. London: Routledge.

BIRESSI, A. e NUNN, H. (2003). "Video justice: crimes of violence in social/media space». In: Space \& Culture, 6 (3): pp. 276-291.

BOBBIO, N. (1982). A teoria das formas de governo. Brasília: UnB.

BOBBIO, N. (2000). O futuro da democracia. São Paulo: Paz e Terra.

BOHMAN, J. (2000). "The division of Labor in Democratic Discourse: Media, Experts, and Deliberative democracy». In: Chambers, S. and Costain, A. N. (org). Deliberation, Democracy and the Media. Maryland: Rowman \& Littlefield Publishers. 
BOTTOMS, A. E. (1995). «The philosophy and politics of punishment and sentencing». In: Clakson, C. and Morgan, R. (eds.). The Politics of Sentencing Reform. Oxford: Clarendon Press.

BRES, J. (2005). "Savoir de quoi on parle: dialogue, dialogal, dialogique; dialogisme, polyphonie...» In: Bres, J.; Haillet, P.P.; Mellet, S.; Nølke, H. e Rosier, L. (dirs.). Dialogisme et polyphonie. Approches linguistiques. Bruxelles: De Boeck.

BRKIC, J. e ANDERSON, N. (1988). Drafting and Interpreting Legal Documents. In: Kevelson, R. (ed.). Law and Semiotics. Vol. 2. New York: Plenum Press.

CALHOUN, C. (1996). "Introduction: Habermas and the public sphere». In: Calhoun, C. (ed.) Habermas and the Public Sphere. 4. ${ }^{\mathrm{a}}$ ed., Cambridge: MIT Press, pp. 1- 48.

CAMPS, V. (2004). «Instituiciones, agencias y mecanismos de supervisión mediática». In: CONILL SANCHO, J.; GONZÁLEZ, V. (coords.). Ética de los Medios - Una apuesta por la ciudadanía audiovisual. Barcelona: Editorial Gedisa.

CANIVET, G. e JOLY-HURARD, J. (2004). La déontologie des magistrats. Paris: Dalloz.

CANotilho, G. e MOReira, V. (2007). Constituição da República Portuguesa Anotada, vol. I. Coimbra: Coimbra Editora.

CARAPINHA, M. C. (2006). Contributos para a análise da linguagem jurídica e da interacção verbal em sala de audiências. Dissertação de Doutoramento (não publ.). Coimbra: Faculdade de Letras.

CARMO, R. do (2005). "O dever de reserva - O dever de informar: algumas achas para o debate». In: AA VV, Balanço da reforma da acção executiva. Segredo de justiça e dever de reserva (Conselho Superior da Magistratura, II Encontro Anual -2004). Coimbra: Coimbra Editora, pp. 155-162.

CARPINI, M. D. e WILliAMS, B. A. (2001). «Let Us Infotain You: Politics in the New Media Environment». In: Bennet, W. L.; Entman, R. M. (eds). Mediated politics: communication in the future of democracy. Cambridge: Cambridge University Press, pp. 160-181.

CASTELLS, M. (1999). O poder da identidade (A era da informação: economia, sociedade e cultura; v.2). São Paulo: Paz e Terra.

CHERMAK, S. M. (1995). Victims in the News. Crime and the American News Media. Boulder, San Francisco, Oxford: Westview.

CHIBNALL, S. (1977). Law-and-Order News: An Analysis of Crime Reporting in the British Press. London: Tavistock Publications.

CHRISTIE, G. C. (1964). "Vagueness and Legal Language». In: Minnesota Law Review, 48.

COHEN, J. (1997). Deliberative Democracy. Cambridge: MIT Press.

COHEN, J. (2009). "Deliberação e legitimidade democrática». In: Marques, A. (ed.). A Deliberação Pública e suas Dimensões Sociais, Políticas e Comunicativas. Belo Horizonte: Autêntica Editora.

COHEN, S. (2002). Folk Devils and Moral Panics. The Creation of the Mods and Rockers, 3. ${ }^{\mathrm{a}}$ ed. London, New York: Routledge.

COHEN, S. e YOUNG, J. (1973). The Manufature of News: Deviance, Social Problems and the Mass Media. London: Constable.

CONSELHO REGULADOR (2006). Parecer Relativo ao Anteprojecto da Proposta de Lei que Altera o Estatuto dos Jornalista - Parecer 2/2006.

CORNU, G. (2000). Linguistique Juridique. $2^{\text {a }}$. Ed. Paris: Montchrestien.

CORNU, D. (1994). Journalisme et Vérité. Genebra: Labor et Fides.

CORREIA, J. C. (2005). Sociedade e Comunicação: Estudos sobre Jornalismo e Identidades. Covilhã: UBI. 
COULTHARD, M. e JOHNSON, A. (2007). An Introduction to Forensic Linguistics. Language in Evidence. London: Routledge.

COUlthARD, M. e JOHNSON, A. (eds.) (2010). The Routledge Handbook of Forensic Linguistics. London: Routledge.

CURTIS, P. (2001). Jack the Ripper and the London press. New Haven: Yale University Press.

DOUGLAS, M. (1986). How Institutions Think. New York: Syracuse University Press.

DRYZEK, J. (2004). "Legitimacy and economy in deliberative democracy» In: Farrely, C. Contemporary Political Theory: a Reader. London: Sage.

DRYZEK, J. (2000). Deliberative Democracy and Beyond: Liberals, Critics, Contestations. Oxford: Oxford University Press.

DUBOUCHET, P. (1990). Sémiotique Juridique. Paris: PUF.

DUCROT, O. (1982). La notion de sujet parlant. In: Cahier du Groupe de Recherches sur la Philosophie et le langage, 2. Grenoble: Université de Grenoble.

DUCROT, O. (1984). Le Dire et le dit. Paris: Minuit.

DURKHeIM, É. (1977). A Divisão do Trabalho Social, Vol. 1, trad. de M. I. Freitas. Lisboa: Editorial Presença.

EAGLETON, T. (2000). Ideology: an Introduction. 7. ${ }^{\mathrm{a}}$ ed. London: Verso.

ELSTER, J. (1986). "The Market and the Forum: Three Varieties of Political Theory". In: Elster, J.; Hylland, A. (eds). Foundations of Social Choice Theory, Cambridge: Cambridge University Press, pp. 104-132.

ELSTER, J. (1998). Deliberative Democracy. Cambridge: Cambridge University Press.

ERICSON, R., BARANEK, P. e CHAN, J. (1989). Negotiating Control: A Study of News Sources. Toronto: University of Toronto Press.

ESSER, F. (1999). "Tabloidization of news. A comparative analysis of Anglo-American and German Press Journalism». In: European Journal of Communication, pp. 291-324.

FARIA, J. E. (1986). "A Reforma do Ensino Jurídico». In: Revista Crítica de Ciências Sociais, 21.

FERNANDES, P. C. (2008). "Justiça e media: legitimação pela comunicação». In: Revista do CEJ $\left(n .^{\circ} 10\right)$, pp. 311-346.

FIGUEIREDO, C. e COSTA, R. (1990). "Alta Autoridade da discórdia». In: Expresso - Suplemento A4, 27 de janeiro.

FONSECA, J. (1994). "O lugar da Pragmática na Teoria e na Análise Linguísticas». In: Pragmática Linguística. Introdução, Teoria e Descrição do Português. Porto: Colecção Linguística/Porto Editora, n. ${ }^{\circ} 5$.

FOUCAUlT, M. (1991). Vigiar e Punir: Nascimento da Prisão. 9. ${ }^{a}$ ed., trad. de L. M. P. Vassallo. Petrópolis: Vozes.

FOX, R. L. e SICKEL, R. V. (2001). Tabloid Justice: Criminal Justice in an Age of Media Frenzy. London: Lynne Rienner Publishers Boulder.

FRANKLIN, B. (1997). Newszak \& News Media. London: Hodder Arnold.

FRASER, N. (1996). "Rethinking the public sphere: a contribution to the critique of actually existing democracy» In: Calhoun, C (ed.) Habermas and the Public Sphere. 4. ${ }^{a}$ ed., Cambridge: MIT Press, pp. 109-142.

FRIEDMAN, L. M. (1964-1965). Law and its Language. In: George Washington Law Review, p. 33.

FUENTES GONZÁLEZ, D. (1997). Algunas aportaciones de la sociolingüística al campo del derecho. In: Delgado León, F.; Calero Vaquera, M. L. e Osuna García, F. (eds.), (1998). 
Actas del II Simposio de Historiografía Lingüística. Córdoba: Servicio de Publicaciones de la Universidad de Córdoba.

GALVÃO TELLES, I. (2000). Introdução ao Estudo do Direito. Vol. II. 10 ${ }^{\mathrm{a}}$ ed. Coimbra: Coimbra Editora.

GARAPON, A. (1998). O guardador de promessas. Lisboa: Instituto Piaget.

GARLAND, D. (2001). The Culture of Control. Oxford: Oxford University Press.

GARMENT, S. (1991). Scandal: The Culture of Mistrust in American Politics. New York: Times Books.

GEYH, C. G. (2006). Preserving Public Confidence in the Courts in an Age of Individual Rights and Public Skepticism. http://ssrn.com/abstract=933699: Indiana University School of Law-Bloomington.

GIBBONS, J. (ed.) (1994). Language and the Law. London: Longman.

GIBBONS, J. (2003). Forensic Linguistics. An Introduction to Language in the Justice System. Oxford: Blackwell.

GIBBONS, J. e TURELL, M. T. (eds.) (2008). Dimensions of Forensic Linguistics. Amsterdam: John Benjamins Publishing Company.

GOLDMAN, L. (1994). Accident and absolute liability in anthropology. In: Gibbons (ed.). Language and the Law. London: Longman.

GOODRICH, P. (1987). Legal discourse. Studies in Linguistics, Rhetoric and Legal Analysis. London: Macmillan.

GRABER, D. A. (1980). Crime News and the Public. New York: Praeger.

GREER, C. e JEWKES, Y. (2005). "Extremes of Otherness: Media Images of Social Exclusion». In: Social Justice, 32 (1), pp. 20-31.

GREIMAS, A. J. (1976). Analyse sémiotique d'un discours juridique. In Greimas, A. J.. Sémiotique et sciences sociales. Paris: Seuil.

GRICE, P. (1975). Logic and Conversation. In: Cole, P.; Morgan, J. L. (eds.). Syntax and Semantics 3: Speech Acts. New York: Academic Press.

GUTMANN, A. e THOMPSON, D. (2007), "O que significa democracia deliberativa", In: Revista Brasileira de Estudos Constitucionais, Belo Horizonte, Ed. Fórum, 2007, pp. 17-78.

HABERMAS, J. (1996). Between Facts and Norms. Contributions to a Discourse Theory of Law and Democracy, Cambridge, MA: MIT Press.

HABERMAS, J. (1996), "Three Normative Models of Democracy» In: Benhabib, S. (ed.) Democracy and Difference. Princeton, NJ: Princeton University Press.

HABERMAS, J. (1997). Direito e Democracia - Entre facticidade e validade, vol. II. Rio de Janeiro.

HABERMAS, J. (1998). The Structural Transformation of the Public Sphere: An Inquiry into a Category of Bourgeois Society, 9. ${ }^{\mathrm{a}}$ reimp., trad. de T. Burger. Cambridge, MA: MIT Press.

HABERMAS, J. (2002). "Prefacio a la Nueva Edición Alemana de 1990". In: Historia y Crítica de la Opinión Pública: La Transformación Estructural de la Vida Pública, trad. de F. Gil Martín, $7^{\text {a }}$. reimp., Barcelona: Gustavo Gilli.

HALl, S., CRITCHER, C., JEFFERSON, T., CLARKE, J. e ROBERTS, B. (1978). Policing the Crisis: Mugging, the State, and Law and Order, London: The MacMillan Press.

HARRIS, S. (1994). Ideological exchanges in British magistrates courts. In: Gibbons, J. (ed.). Language and the Law. London: Longman.

HJARVARD, S. (2008). "The Mediatization of Society: a Theory of the Media as Agents of Social and Cultural Change». In: Nordicom Review 29, 2, pp. 105-134. 
HOEY, M (1985). "The Statute as Discourse and the Lawyer as Linguist». In: Hall, R. A. J. (ed.) The Eleventh LACUS Forum 1984. Columbia: Hornbeam Press.

HONNETH, A. (1995). The Fragmented World of the Social: Essays in Social and Political Philosophy. New York: SUNY Press.

HUTCHINGS, P. (1999). «Spectacularizing crime: ghostwriting the law». In: Law and Critique, 10: pp. 27-48.

JACKSON, B. S. (1995). Making Sense in Law. Linguistic, Psychological and Semiotic Perspectives. Liverpool: Deborah Charles Publications.

JALALI, C. (2005). "Nova governação nova cidadania? Os cidadãos e a política em Portugal». In: Revista de Estudos Politécnicos, vol. II, n. ${ }^{\circ} 4$.

JIMÉNEZ, F. J. (1994). «Posibilidades y limites del escandalo politico como una forma de control social». In: REIS Revista Española de Investigaciones Sociológicas, pp. 7-36.

KELSEN, H. (1934). "The pure theory of law, its methods and fundamental concepts". In: Law Quarterly Review, n. ${ }^{\circ} 50$.

KISSELER, L., e HEIDEMANN, F. (2006). «Governança pública: novo modelo regulatório para as relações entre Estado, mercado e sociedade?». In: Revista da Administração Pública, 40 (3), Rio de Janeiro, Maio/Junho.

LAMBERT, P. (2004). "Le devoir de réserve et les notions voisines». In: AA VV. Actes de la Table Ronde organisée par l' Institut d'Études sur la Justice, le 17 octobre 2003, Bruxelles: Bruylant, pp. 9-19.

LEVI, J. N. e WALKer, A. G. (eds.) (1990). Language in the Judicial Process. New York: Plenum Press.

MACHADO, H. e SANTOS, F. (2009). A moral da justiça e a moral dos media: Julgamentos mediáticos e dramas públicos (Oficina do CES $n .^{\circ} 333$ ). Coimbra: CES.

MACHADO, H. e SANTOS, F. (2008). Crime, drama e entretenimento. O caso Maddie e a meta-justiça popular na imprensa portuguesa (Oficina do CES n. ${ }^{\circ}$ 308). Coimbra: CES.

Machado, J. (2002). Liberdade de Expressão. Dimensões constitucionais da esfera pública no sistema social. Coimbra: Coimbra Editora.

MACHADO, J. B. (2002). Introdução ao Direito e ao Discurso Legitimador. (13 $3^{\mathrm{a}}$ reimp.) Coimbra: Almedina.

MALEY, Y. (1994). The Language of the Law. In: Gibbons, J. (ed.). Language and the Law. London: Longman.

MANIN, B. (1987). "On Legitimacy and Political Deliberation». In: Political Theory, 15, pp 338-368.

MANSBRIDGE, J. (1999). "Everyday talk in deliberative system» In: Macedo, S. (ed.). Deliberative Politics: Essays on Democracy and Disagreement. New York: Oxford University Press.

MARMOR, A. (2008). "What Does the Law Say?»In: Analisi e diritto 2007. Ricerche di giurisprudenza analitica. Torino: G. Giappichelli Editore.

MASCARENHAS, Ó. (1998) "Por uma carta 98 da auto-regulação». In: AAVV. $3 .^{\circ}$ Congresso dos Jornalistas Portugueses - Conclusões, teses, documentos, Lisboa, Comissão Executiva do III Congresso dos Jornalistas Portugueses.

MASON, P. (2006) «Lies, distortion and what doesn't work: monitoring prison stories in the British media». In: Crime Media Culture, 2 (3), pp. 251-267.

MATHIESEN, T. (1995). "The eagle and the sun: on panoptical systems and mass media in modern society». In: Ericson, R. (ed.) Crime and the Media. Aldershot, Brookfield USA, Singapore, Sydney: Dartmouth, pp. 333-350. 
MATHIESEN, T. (2004). Essays on the creation of Acquiescense in Modern Society, Winchester: Waterside Press.

MATHIESEN, T. (2006). Prison on Trial, $3^{\mathrm{a}}$. ed., Winchester: Waterside Press.

MATOS, F. A. (2011). Responsabilidade Civil por Ofensa ao Crédito ou ao Bom Nome. Coimbra: Almedina.

MESQUITA, J. (1998). "Aprofundar a autonomia", In: AAVV. 3. ${ }^{\circ}$ Congresso dos Jornalistas Portugueses - Conclusões, teses, documentos. Lisboa: Comissão do III Congresso dos Jornalistas Portugueses.

MOREIRA, V. (1997). Auto-Regulação Profissional e Administração Pública. Coimbra: Almedina, 1997.

NEWBURN, T. e JONES, T. (2007). "Symbolizing crime control». In: Theoretical Criminology, 11(2), pp. 21-243.

OLSSON, J.(2004). Forensic Linguistics. An Introduction to Language, Crime and the Law. London: Continuum.

PAIXÃO, B. (2010). O escândalo político em Portugal (1991-1993 e 2002-2004). Coimbra: Minerva.

PATON, W. R. (1922). Polybius: The Histories, Volume III, Books 5-8 (Loeb Classical Library). London: Heinemann.

PRATT, J. (2007). Penal Populism, London, New York: Routledge.

PUTMAN, E. (1997). "Éthique des affaires et déontologie des professions d'affaires: réflexions sur la morale des marchands». In: BERGEL, J-L. (org.). Droit et Déontologies Professionnelles. Aix-en-Provence: Librairie de l'Université.

RAWLS, J. (1971). A Theory of Justice. Harvard: Harvard University Press.

RAWLS, J. (2001). O Direito dos Povos. São Paulo: Martins Fontes.

RIVERA BEIRAS, I. (2003). "State form, labor market and penal system: the new punitive rationality in context». In: Punishment Society, 7(2), pp. 167-182.

SANDERS, L. (1997). "Against deliberation». In: Political Theory, 25, pp. 347-376.

SANTOS, B. S. et al. (2009). A Justiça Penal: Uma Reforma em Avaliação. Coimbra: Centro de Estudos Sociais da Faculdade de Economia da Universidade de Coimbra.

SCHLESINGER, P. e TUMBER, H. (1994). Reporting Crime: The Media Politics of Criminal Justice. Oxford: Clarendon Press.

SCHLESINGER, P., TUMBER, H. e Murdock, G. (1995). "The media politics of crime and criminal justice». In: ERICSON, R. (coord.) Crime and the Media. Aldershot, Brokfield USA, Singapore, Sydney: Dartmouth, pp 397-420.

SCHUDSON, M. (1978). Discovering the news: a social history of American newspapers. New York: Basic Books.

SCHULZ, W. (2004). "Reconstructing Mediatization as an Analytical Concept». In: European Jounal of Communication Vol 19 (1), pp. 87-101.

SCHUMPETER, J. A. (1994). Capitalism, Socialism, and Democracy. London: Routledge.

SERRANO, E. (2007). "Pensar a regulação dos media numa sociedade em mudança». In: Comunicação e Sociedade ("Regulação dos media em Portugal»), vol. 11, Braga.

SHAPIRO, I. (1999). "Enough of deliberation: politics is about interest and power". In: Macedo, S. (ed.), Deliberative Politics: Essays on Democracy and Disagreement. New York: Oxford University Press.

SHETREET, S. e DESCHÊNES, J. (eds) (1985). Judicial Independence; the contemporary debate. Amsterdam: Martinus Nijhoff. 
SILVA, A. S., (2007). "A hetero-regulação dos meios de comunicação social». In: Comunicação e Sociedade, vol. 11, Braga.

SILVA, V. J. (2006). "Ordem e desordem jornalística». In: Diário de Notícias, 29 de Março.

SILVEIRINHA, M. J. (2004). Identidades, Media e Política: O Espaço Comunicacional nas Democracias Liberais, Lisboa: Livros Horizonte.

SILVEIRINHA, M. J. (2005). "Democracia deliberativa e reconhecimento: repensar o espaço político». In: Correia, J. C. Comunicação e Política. Covilhã: UBI.

SOURIOUX, J-L e LERAT, P. (1975). Le langage du droit. Paris: PUF.

STOFFEL-MUNCK, P., (1997). "Déontologie et moral». In: Bergel, J-L. (org.), Droit et Déontologies Professionnelles. Aix-en-Provence: Librairie de l'Université.

STYGALL, G. (2010). "Legal writing: complexity. Complex documents/average and not-so-average readers". In: Coulthard, M.; Johnson, A. (eds.) (2010). The Routledge Handbook of Forensic Linguistics. London: Routledge.

SURETTE, R. (2010). Media, crime, and criminal justice: images, realities and policies. $4 .{ }^{a}$ ed. Belmont: Wadsworth.

THOMAS, J. (1997). Judicial Ethics in Australia. Sydney: Law Book Co.

THOMPSON, J. (2005). "The new visibility". In: Theory, Culture E Society, 22(6),pp. 31-51.

THOMPSON, J. B. (2002). O escândalo político: poder e visibilidade na era da mídia. Petrópolis: Editora Vozes.

THORNTON, G. C. (1996). Legislative Drafting. London: Butterworth.

THUSSU, D. K. (2007). News as entertainment: the rise of global infotainment. London: Sage.

TIERSMA, P. M. (1993). «Linguistic Issues in the law». In: Language, 69, pp. 113-137.

TIERSMA, P. M. (2000). Legal Language. Chicago: The University of Chicago Press.

VALIER, C. (2002). Theories of Crime and Punishment. Harlow, New York: Longman.

VAN DIJK, T. A. (1990). La Noticia como Discurso: Comprensión, Estructura y Producción de la Información, Paidós: Barcelona.

VAN DIJK, T. A. (2005). Discurso, Notícia e Ideologia: Estudos na Análise Crítica do Discurso, trad. de Z. P. Coelho, Porto: Campo das Letras.

VAN OMMESLACHE, P. (1995) “L'autorégulation». In: AAVV, L'Autorégulation. Bruxelas: Bruylant.

VERDUSSEN, M. (2004). "Le devoir de réserve au regard de la jurisprudence de la Cour Européenne des Droits de l'Homme». In: AA VV, Actes de la Table Ronde organisée par l' Institut d' Études sur la Justice, le 17 Octobre 2003. Bruxelles: Bruylant, pp. 21-31.

VILlEY, M. (1974). "Préface». In: Archives de Philosophie du Droit, Tome XIX.

VILLEY, M., KALINOWSKI, G. e GARDIES, J-L. (1974). "Indicatif et impératif juridiques. Dialogue à trois voix". In: Archives de Philosophie du Droit, Tome XIX.

VIRALlY, M. (1966). "Le phénomène juridique». In: Revue de Droit Public.

WACQUANT L. (2001). "How penal common sense comes to Europeans: notes on the transatlantic diffusion of neoliberal doxa». In: European Societies, 1 (3), pp. 319-352.

WEICHER, M. E. e GOLDSCHMIDT, J. (2007). "The Expansion of the First Amendment in Judicial Elections: Another Cause for Reform». In: Loyola University Chicago Law Journal, pp. 833-894.

WEICK, K. E. (1995). Sensemaking in Organizations. London: Sage. 
WIENER, J. (1988). Papers for the millions; the new journalism in Britain, 1850-1914. New York: Greenwood.

WIIO, O. A. (1995). "Organizational communication. Contingent views». In: Goldhaber G.M.; Barnett G. A. (eds.). Handbook of Organizational Communication. Norwood: Ablex.

WILliAMS, G. (1945). Language and the Law (artigo em 5 partes). In: The Law Quarterly Review 61 (4 partes) e 62 (5. ${ }^{\mathrm{a}}$ parte).

WOLTON, D. (1995). "As contradições do espaço público mediatizado". In: Revista de Comunicação e Linguagens, 21-22, pp. 167-188.

YOUNG, I. M. (2000). Inclusion and Democracy. Oxford: Oxford University Press. 